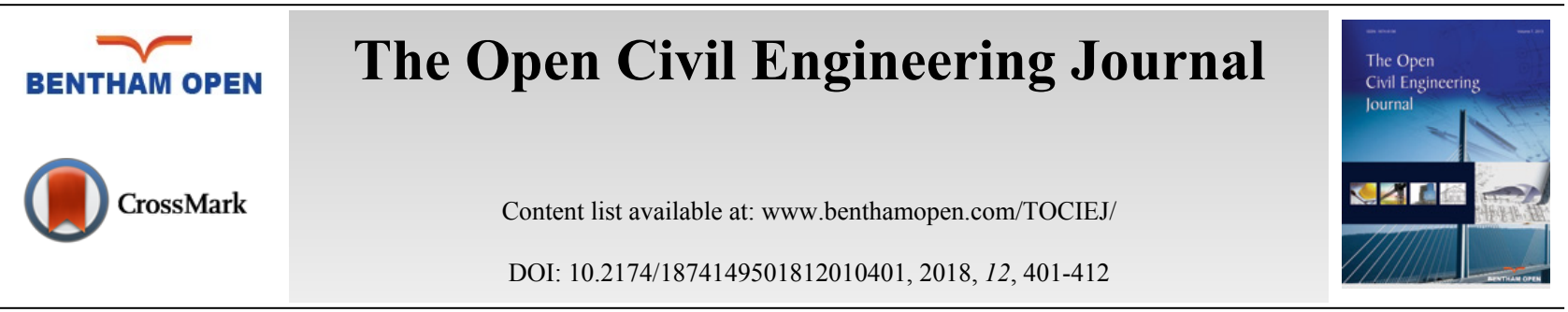

RESEARCH ARTICLE

\title{
Study of a New Plaster Composite Based on Dune Sand and Expanded Polystyrene as Aggregates
}

Hamza Laoubi ${ }^{1}$, Madani Bederina ${ }^{1,3, *}$, Amina Djoudi ${ }^{2}$, Adeline Goullieux $^{3}$, Rose Marie Dheilly ${ }^{3}$ and Michele Queneudec ${ }^{3}$

${ }^{I}$ Structures Rehabilitation and Materials Laboratory, Civil Engineering Department, University of Amar Telidji, Routes de Ghardaia, 03000, Laghouat, Algeria

${ }^{2}$ Civil Engineering laboratory, University A. Telidji, Routes de Ghardaia, 03000, Laghouat, Algeria

${ }^{3}$ Research Unit “EPROAD”, University Jules Vernes of Picardie, Rue Saint Leu 80039 Amiens, Cedex 1, Amiens, France

\section{Abstract:}

\section{Introduction:}

This study aims to highlight the physicomechanical properties of a new lightweight construction material which is composed of plaster as a binder and dune sand and Expanded Polystyrene Beads (EPS) as aggregates.

\section{Methods:}

For this purpose, different mixtures were designed with different percentages and particle sizes of EPS aggregates in order to test the porosity, the density and the thermo-mechanical properties of the studied composite. Furthermore, Electron Microscopy (EM) visualisation and SEM analysis were used for the study of the structure and the interface "paste-aggregates".

\section{Results and Conclusion:}

The obtained results showed that the progressive incorporation of an increasing percentage of PSE decreases the density of the plaster composite and consequently improves its thermal properties. As expected, the mechanical strength decreases with the increase of the EPS content, but relatively good mechanical strength can be obtained with low quantities of EPS. Concerning the material structure, it should be noted that the composite appears more or less homogeneous and the EPS beads adhere well to the plaster matrix.

Keywords: Plaster Concrete/mortar, Expanded Polystyrene, Dune Sand, Density, Thermal Properties, Mechanical Properties, Structure.

\section{INTRODUCTION}

It is well known that the essential characteristic of the lightweight mortars or the lightweight concrete is their porosity i.e. their low apparent density. Generally, although a high density of concrete/mortar leads to high mechanical properties, reducing it results in considerable other advantages. Indeed, the use of lightweight composites as building materials reduces the demand for energy and the cost during the construction and ensures better thermal insulation than the ordinary composites [1]. Many techniques have been used to lighten concrete/mortars. The use of Lightweight Aggregates (LWA) is one of these techniques [1]. In literature, different types of lightweight aggregates were used. Some of them are natural aggregates such as scoria, volcanic cinders, tuff and diatomite, and others are

\footnotetext{
* Address correspondence to this author at the Civil Engineering Department, University of Amar Telidji, Laghouat, Algeria; Tel: $+213-773732230$; Fax:+213-663-180-114; E-mail: m.bederina@lagh-univ.dz.
} 
artificial aggregates such as expanded clays, slates, slag, perlite orshale's [2 - 8]. The Expanded Polystyrene beads (EPS) which are considered as lightweight cellular plastic material characterized by a porous structure is one of these lightweight aggregates. This material is considered as a non-biodegradable material and its reuse in its waste form, not only leads to technical and economical interests, but also to environmental benefits.

The EPS has already been used as a lightweight aggregate by different authors in the case of the cementitious matrices [1 - 3]. The obtained results showed that the cement composites based on polystyrene aggregates presented acceptable mechanical strengths with excellent thermal insulation. Many attempts have been made in order to improve the mechanical strength of polystyrene concretes using the addition of fly ash, the increase of cement content, the addition of fibers, etc [6,7]. It should be generally noted that the use of expanded polystyrene has been mostly studied in the case of concretes. A few works studied expanded polystyrene mortars, among which are those of Ferrándiz-Mas et al. The latter led many works on mortars containing EPS waste where they studied the physicomechanical properties and the durability [3 - 5]. However, what should be noted is that almost all these works incorporated the EPS-aggregates in cementitious composites. Their use in composites with other binders seems to be made by only San-AntonioGonzález et al. who used the gypsum with EPS waste. They studied a lightweight composite made with gypsum and EPS waste with enhanced mechanical strength [7].

In addition, the valorisation of local materials such as the dune sands that are available in great quantities in the south of Algeria, can, on one hand, reinforce the plaster mortar and on the other hand solve considerable economical problems.

It is in this context that this work has been undertaken. An attempt of introducing dune sand and expanded polystyrene beads in a plaster paste has been led in order to study a new lightweight concrete/mortar.

Finally, the main objective of this work is to study the physicomechanical properties of a new lightweight building material based on a plaster as a binder and a dune sand and expanded polystyrene beads as aggregates. Compared to previous works, the novelty of this work is the use of polystyrene and sand dune all together in a paste based on plaster to form a new lightweight mortar which is very economical and that will solve the problem of thermal insulation in areas arid.

\section{MATERIALS AND METHODS}

\subsection{Materials}

For the preparation of the studied specimens, the following materials were used:

- Plaster: The plaster used in this study is a product of commercial available gypsum. Table $\mathbf{1}$ presents its chemical analysis. According to Table 1, it is clear that the two most dominating species are the $\mathrm{SO}_{2}$ and the $\mathrm{CaO}$, which affirm that the most essential constituent of the used plaster is the calcium sulphate.

- Dune sand: The dune sand $(0 / 0.63 \mathrm{~mm})$, presents a continuous particle size distribution with a very weak fraction of fine elements (Fig. 1). The X-ray Diffraction analysis demonstrates its essentially siliceous nature as shown in Fig. (2) $[8,9]$.

- Expanded Polystyrene: The EPS beads used in this study are an Algerian product fabricated by a local company located in the city of Ain Oussara (Algeria). They appear as perfectly spherical balls as shown in Fig. (3). Their outer surface is smooth and their inside structure is tight which makes them of a hydrophobic character [10]. Thus, they are impermeable to water, even under a high water pressure [11]. Three EPS diameters are used: 3.15 $\mathrm{mm}, 4 \mathrm{~mm}$ and 5-7 $\mathrm{mm}$ Table. 2.

- Air lime: it is selected in this study as a retarder setting of the plaster because it is susceptible to decrease its solubility and increase its time of use, without affecting its mechanical properties.

Table 1. Chemical analysis of the used plaster.

\begin{tabular}{|c|c|c|c|c|c|c|c|c|c|}
\hline Components & $\mathrm{SiO}_{2}$ & $\mathrm{AL}_{2} \mathrm{O}_{3}$ & $\mathrm{Fe}_{2} \mathrm{O}_{3}$ & $\mathrm{CaO}$ & $\mathrm{MgO}$ & $\mathrm{SO}_{2}$ & $\mathrm{Na}_{2} \mathrm{O}$ & $\mathrm{KO}$ & $\mathrm{CL}$ \\
\hline Content (\%) & 0,70 & 0,10 & 0,08 & 32,15 & 0,53 & 44,95 & 0,09 & 0,03 & 0,002 \\
\hline
\end{tabular}


Table 2. Physical properties of the used polystyrene Beads.

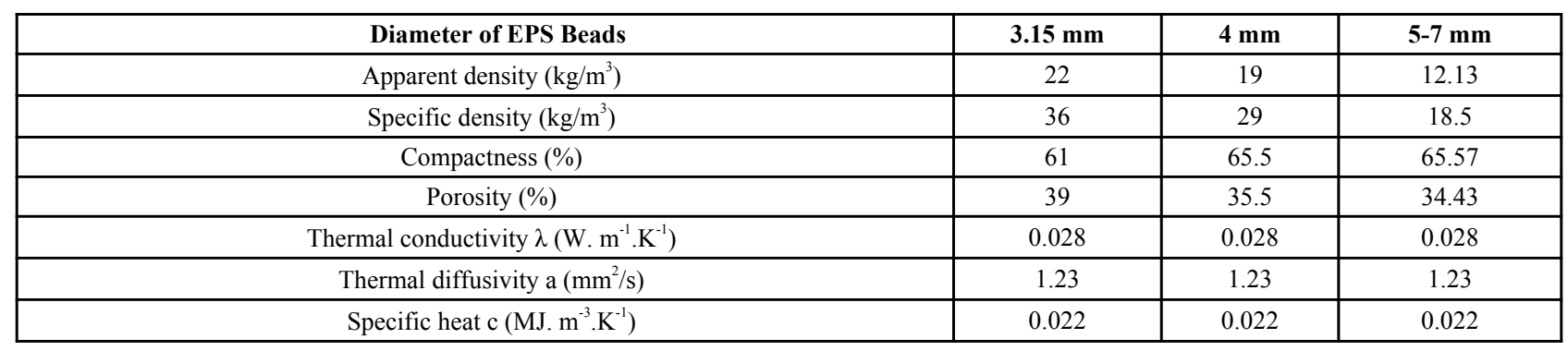

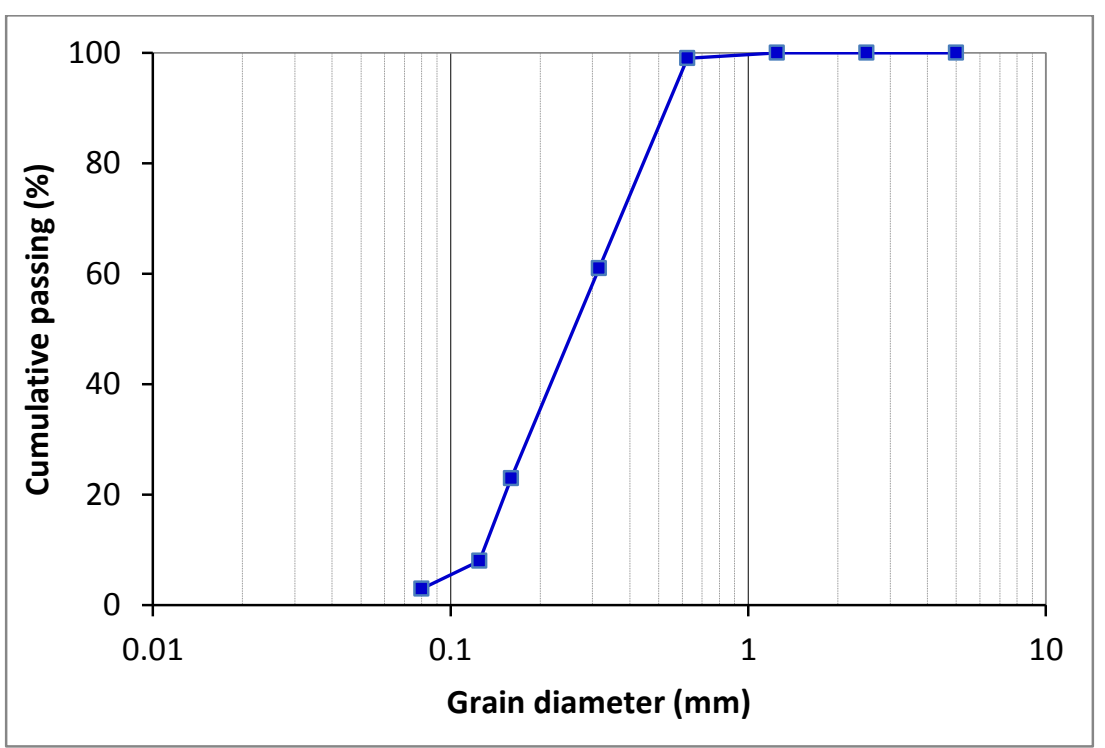

Fig. (1). Particle size distribution of the used sand.

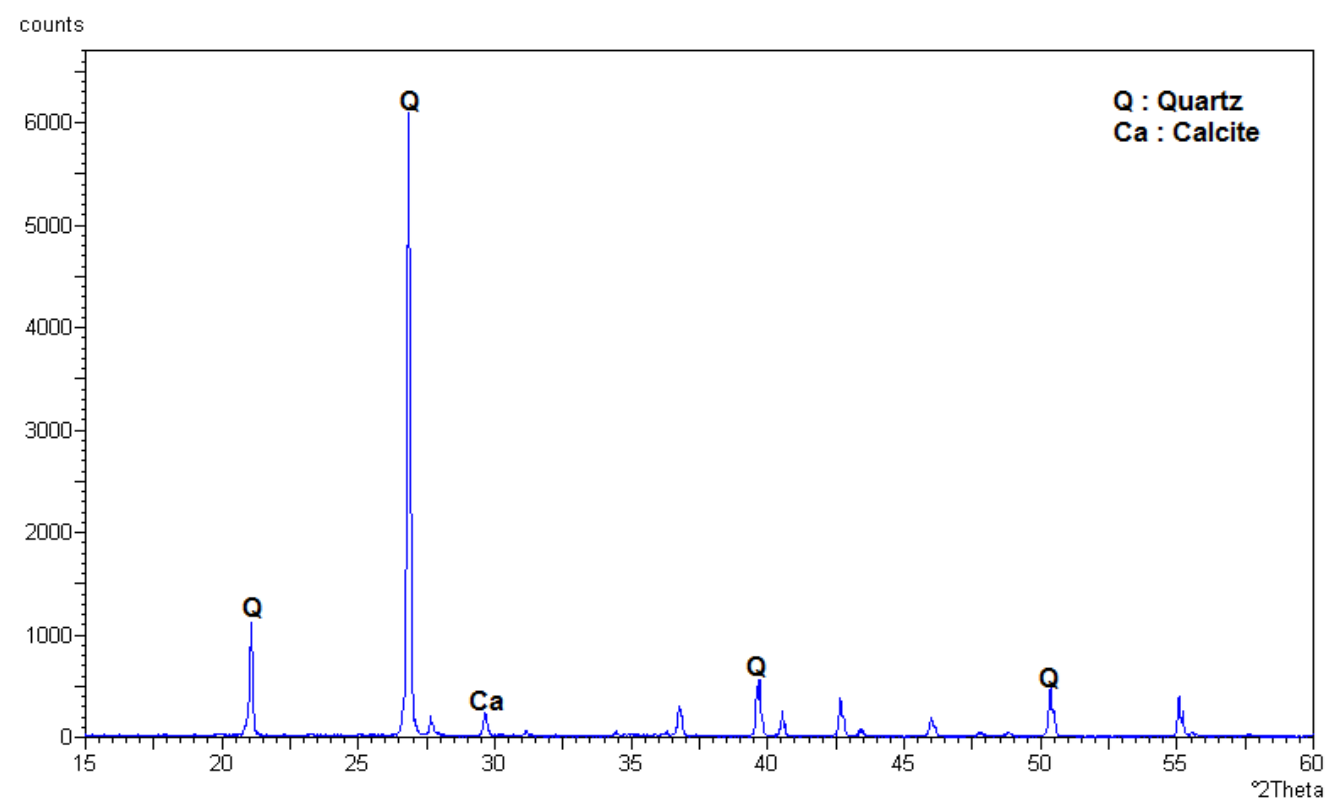

Fig. (2). X-ray diffraction analysis of the used sand. 


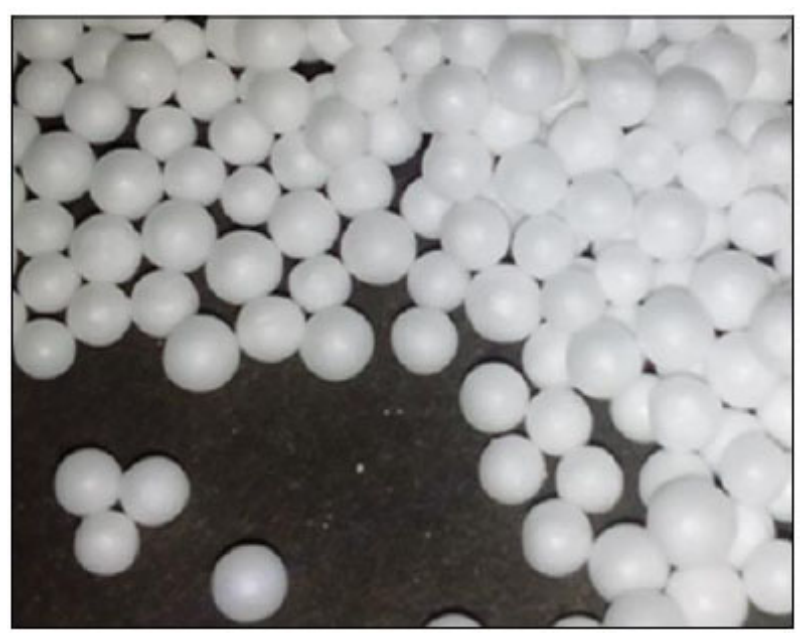

Fig. (3). General aspect of the used polystyrene beads.

\subsection{Samples Preparation and Experimental Methods}

All samples were characterized by their density in dry state, their flexural and compressive strength after 28 days and their thermal conductivity. The latter was measured by the TPS-technique (Transient Plane Source) according to the specification of the European Standards ISO 22007-2 [12] (Fig. 4). To this end, different prismatic specimens (160 $\times$ $40 \times 40) \mathrm{mm}^{3}$ were elaborated. Mix preparation is particularly delicate, especially when using very lightweight aggregates. Regarding the preparation of the plaster mortar, we used the recommendations given by CNERIB (National Centre for Studies and Integrated Researches to Building) [13].

- We fix the plaster/sand ratio at $\mathrm{P} / \mathrm{S}=0.50$ by weight because, according to CNERIB's recommendations [13], an excess in the sand quantity reduces the mechanical properties of the plaster-based materials.

- The EPS beads were incorporated in a matrix consisting of 'plaster + sand'; the percentages, by volume, of the expanded polystyrene (relative to the volume of matrix) varied from 20 to $50 \%$ with steps of $10 \%$. A composition without EPS (reference sample) was also elaborated in order to compare the results obtained. All test specimens were cured at a temperature of $20 \pm 1^{\circ} \mathrm{C}$ and a relative humidity of $45 \pm 1 \%$ for 28 days.

With this restriction, several series of samples, composed with different PSE percentages $(0 \%, 20 \%, 30 \%, 40 \%$ and $50 \%$ ) and three particle sizes $(3.15 \mathrm{~mm} ; 4 \mathrm{~mm} ; 5-7 \mathrm{~mm})$, were defined and analysed, as presented in Table 3.

Table 3. Compositions and test results.

\begin{tabular}{|c|c|c|}
\hline $\begin{array}{l}\text { PSE Particle size } \\
(\mathbf{m m})\end{array}$ & $\begin{array}{c}\text { PSE Percentage } \\
(\%)\end{array}$ & $\begin{array}{l}\text { Density } \\
\left(\mathrm{kg} / \mathrm{m}^{3}\right)\end{array}$ \\
\hline \multirow{5}{*}{3.15} & 0 & 1414 \\
\hline & 20 & 1030 \\
\hline & 30 & 959 \\
\hline & 40 & 797 \\
\hline & 50 & 671 \\
\hline \multirow{4}{*}{4} & 20 & 1017 \\
\hline & 30 & 924 \\
\hline & 40 & 763 \\
\hline & 50 & 679 \\
\hline \multirow{4}{*}{$5-7$} & 20 & 932 \\
\hline & 30 & 832 \\
\hline & 40 & 741 \\
\hline & 50 & 613 \\
\hline
\end{tabular}





Fig. (4). Measurement of the thermal properties of the plaster composite based on the polystyrene beads.

\section{RESULTS AND DISCUSSION}

\subsection{Density}

It is well known that the density is the first indicator to determine if the material can be classified in the lightweight material category or not. In our case, it has been noticed that, after preparation, the value of the density of the studied plaster composite based on expanded polystyrene beads stabilized at the age of 14 days. The measured values of density at 28 days are illustrated by the Fig. (5).

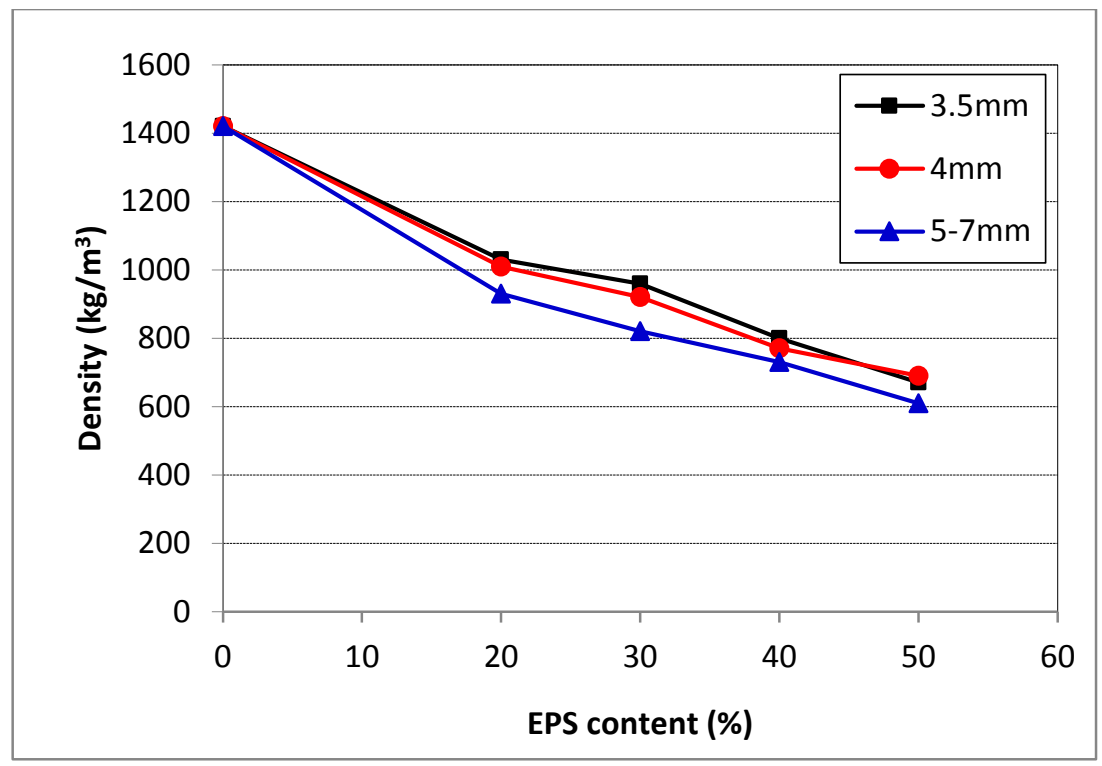

Fig. (5). Evolution of the density of the studied composite versus the proportion and size of the EPS beads.

The progressive incorporation of an increasing percentage of EPS (from 0 to $50 \%$ ) into a matrix composed of plaster and dune sand involves a density reduction between $27.15 \%$ and $56.7 \%\left(613\right.$ and $\left.1414 \mathrm{~kg} / \mathrm{m}^{3}\right)$; this density reduction is due to the partial substitution of plaster - dune sand by the lightweight aggregate. According to Fig. (5), it is also clear that this reduction is slightly higher when the size of EPS beads is higher.

\subsection{Mechanical Strength}

The variations of the flexural and compressive strengths at 28 days of the studied plaster composite according to the proportion and sizes of particles of expanded polystyrene beads are shown in Figs. (6 and 7), respectively. 


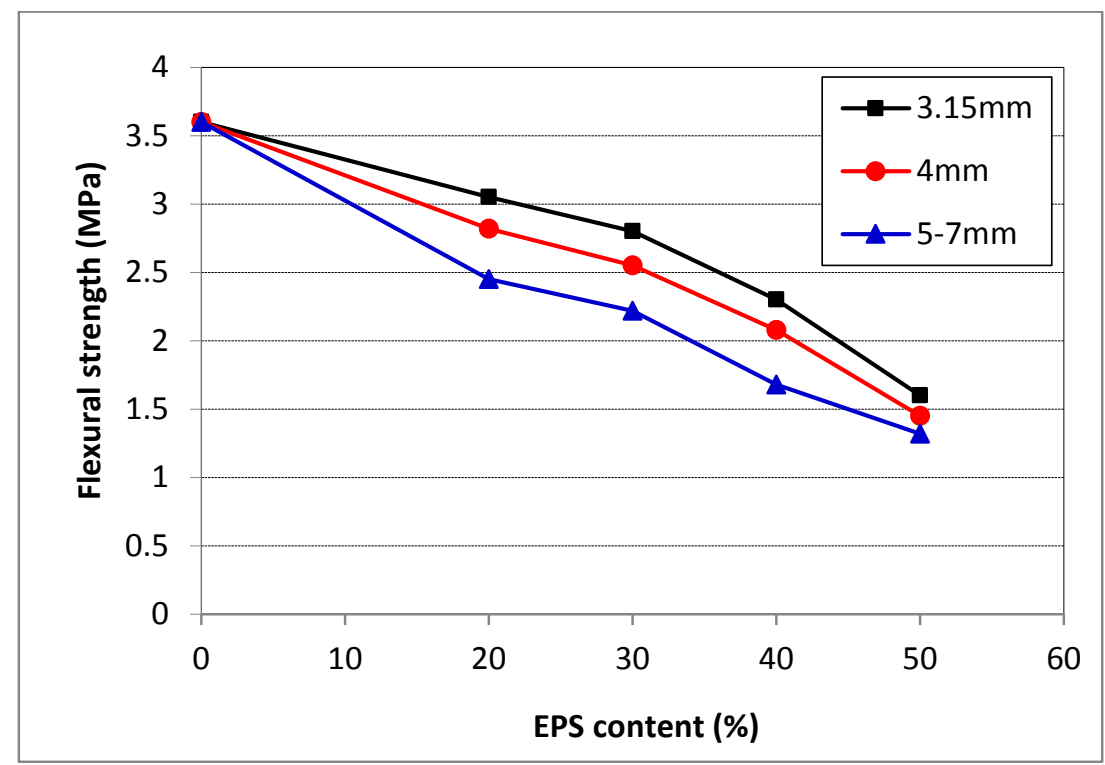

Fig. (6). Variation of the flexural strength of the studied composites according to EPS content and size.



Fig. (7). Variation of the compressive strength of the studied composites according to EPS content and size.

An important strength loss is observed when increasing the EPS addition. The same observation is also made when decreasing the EPS size Figs. (6 and 7).

Samples containing EPS from 3.15 to $4 \mathrm{~mm}$ kept flexural strength values over $1.43 \mathrm{MPa}$ in each case. However, particles of size 5-7 mm with higher percentages of EPS (50\%) showed a significant decrease in resistance that goes up to $62 \%$ (samples with $50 \%$ of EPS).

On the other hand, regarding compressive strength, the results show that the compressive strength decreases with the incorporation of EPS; with the studied EPS proportions, reductions of $11 \%$ and $74 \%$ have been recorded. Moreover, most of the samples with 50\% of EPS 5-7 mm do not fulfill the European Standard EN13279-1 [14], which defines 2 $\mathrm{N} / \mathrm{mm}^{2}$ as the minimum requirement for compressive strength.

It is well known that the decrease in the density of a building material significantly decreases its mechanical strength. In this study, it is also clear that the mechanical strength of the studied plaster composite decreases with the decrease of its density. An example is shown in Fig. (8), where the flexural strength and the density of two samples made separately with two different sizes of EPS $(3.15 \mathrm{~mm}$ and 5-7 $\mathrm{mm})$ were compared. 


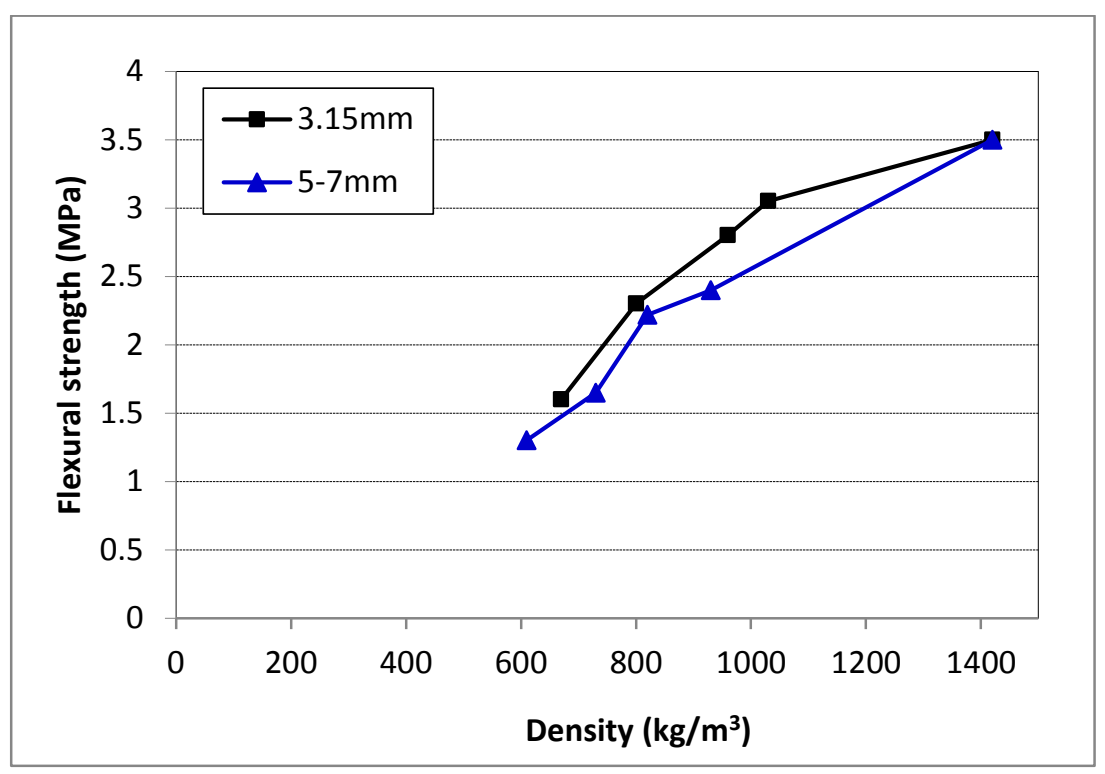

Fig. (8). Relationship between the density and the flexural strength of the studied composite for different EPS sizes.

This reduction in mechanical strength is due to the fact that dune sand grains (hard and more resistant mineral materials) are partially replaced with polystyrene beads (flexible and less resistant). In the case of compression, that reduction is due firstly to the weakness of the expanded polystyrene beads in compression and their high flexibility compared to that of the matrix, and secondly to the fact that polystyrene does not react chemically with the mix to contribute to the composite strength. However, in the cases of flexion, the reduction can be due to the weak adhesion between the plaster paste and the polystyrene beads compared to that between plaster paste and dune sand. Indeed, if the adhesion 'polystyrene - matrix' was better, it should be possible to obtain better flexural strengths thanks to the high flexibility of the polystyrene. Moreover, it should be noted that, in the cases of polystyrene aggregates, the failure mode of the specimens under compressive/flexural load did not exhibit the typical brittle failure as in the case of mineral aggregates. With polystyrene aggregates, the failure seems to be more gradual and compressible, which shows the good energy absorption capacity of the studied expanded polystyrene composite $[1,15]$.

Furthermore, it should be noted that the obtained values are in agreement with the standards required by the functional classification of RILEM [15] for an insulating building material.

These values are also consistent with the standards required by the ACI 213R-87 [16] for a low strength lightweight concrete (a density $\rho=300-800 \mathrm{~kg} / \mathrm{m}^{3}$ and a compressive strength $\mathrm{Rc}<7 \mathrm{MPa}$ ). Indeed, in the case where a higher mechanical strength is required, the problem of low mechanical properties of lightweight concrete/mortar containing polystyrene aggregates can be solved by the use of a mineral addition, a special admixture, fibers, other techniques of setting up, etc.

Finally and unlike the case of mineral aggregates, with finer EPS, better mechanical properties can generally be obtained (case of $\mathrm{D}=3.15 \mathrm{~mm}$ ).

\subsection{Thermal Conductivity}

Fig. (9) shows the thermal conductivity results for the different studied composites (different EPS sizes and proportions). The lowest thermal conductivity, which is $0.198 \mathrm{~W} \cdot \mathrm{m}^{-1} \cdot \mathrm{k}^{-1}$, is obtained with an addition of $50 \%$ of expanded polystyrene beads for particle size 5-7 $\mathrm{mm}$.

According to Fig. (9), it is found that the thermal conductivity decreases as the percentage of expanded polystyrene increases. That is quite normal since mineral aggregates (dune sand) were replaced by polystyrene beads which are characterized by lower thermal conductivity. Let us note that the obtained values are consistent with those of the literature.

Moreover, even the thermal conductivity obtained with the control plaster composite (without polystyrene) complies with the recommendations of RILEM which advocates for a lightweight concrete of construction and insulation (class II), a thermal conductivity less than $0.75 \mathrm{~W} \cdot \mathrm{m}^{-1} \cdot \mathrm{k}^{-1}[15]$. The addition of the expanded polystyrene beads further 
decreases it. With high proportions of expanded polystyrene beads, it was possible to obtain thermal conductivities less than $0.30 \mathrm{~W} \cdot \mathrm{m}^{-1} \cdot \mathrm{k}^{-1}$.

Since the higher the expanded polystyrene beads content, lower is the density of plaster composite and consequently the thermal conductivity, it can be deduced that the addition of the expanded polystyrene beads plays an important role in the lightening of the concrete/mortar and the reduction of its thermal conductivity $(\lambda)$.

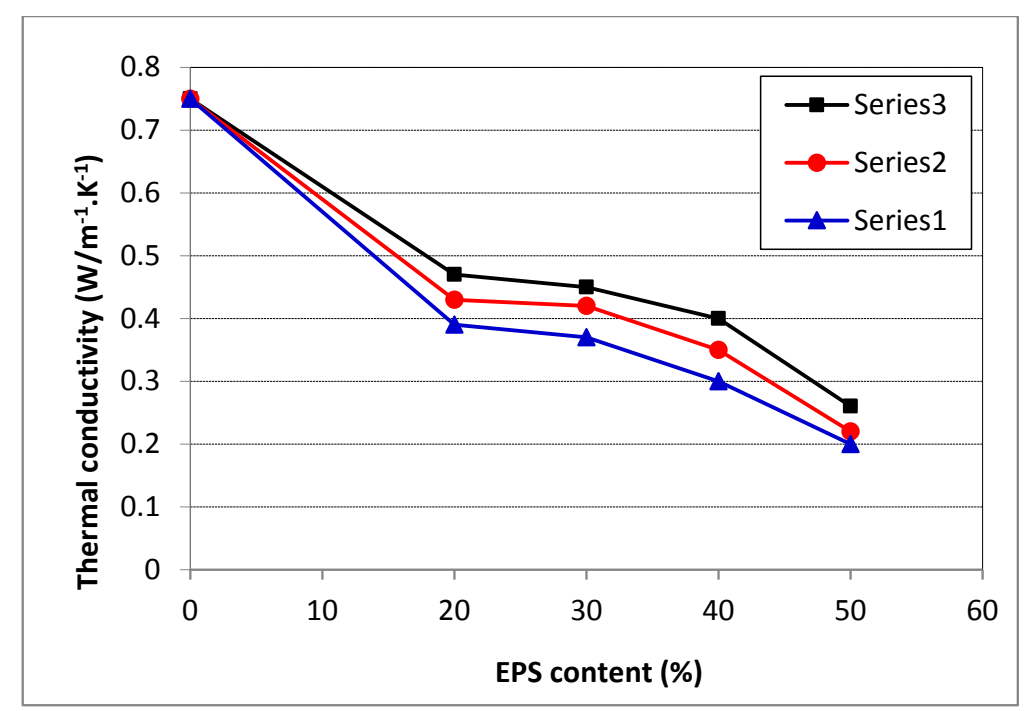

Fig. (9). Variation of the thermal conductivity $(\lambda)$ of the studied composite according to the percentage of the polystyrene beads and EPS size.

\subsection{General Aspect and Structure of the Composite}

Regarding the structure aspect of the studied composite, (Fig. 10) shows that, in general, the material presents relatively a homogeneous texture. Indeed, the polystyrene particles appear well distributed in the plaster matrix which means that there is no segregation during the casting of the concrete/mortar in molds. Contrary to the cementitious composites, where it has been noticed the floating and the segregation of expanded polystyrene beads [17 - 19], in the case of the plaster composites there is not a great problem of floating and segregation thanks to the fact that the plaster paste is lighter than the cement paste. Moreover, the adhesion between the plaster matrix and the expanded polystyrene beads seems to be more or less good. The expanded polystyrene aggregates appear well wrapped in the matrix.

In addition, exactly as in the case of composite with mineral aggregates, it can be noticed that in the bending test, the expanded polystyrene beads do not break and the crack propagates through the interface "polystyrene-matrix" (Fig. 10).

As regards the dune sand grains, it is clear that they are also well distributed in the plaster paste with a good adhesion "plaster - sand". These findings are also in agreement with those of the literature. It should be finally noted that even the cork aggregates which have a similar physical aspect with the polystyrene, adhere well to cementitious matrix [20].

In addition, SEM-analyses were made on various points of the studied composite. The analysis of the interface "sand - plaster" showed a good adhesion between the sand grains and the plaster paste. Indeed, no gaps have been observed between these two components (Fig. 11a). Moreover, interface EPS/matrix analysis showed a good adhesion between the EPS beads and the plaster matrix; no gaps have been observed between these two components (Fig. 11b). On the other hand, in Fig. (11b), it is possible to observe the porous structure of EPS which lies behind the main results obtained in this study.

Fig. (11a) shows also the morphology of the crystals thus formed in the matrix which is, indeed, a result of the conditions of paste hydration. It is clear that only needle shapes (gypsite crystals) are present in the matrix. These needles appear well-entangled and well interfered which give to the plaster its binding character as a building material. 


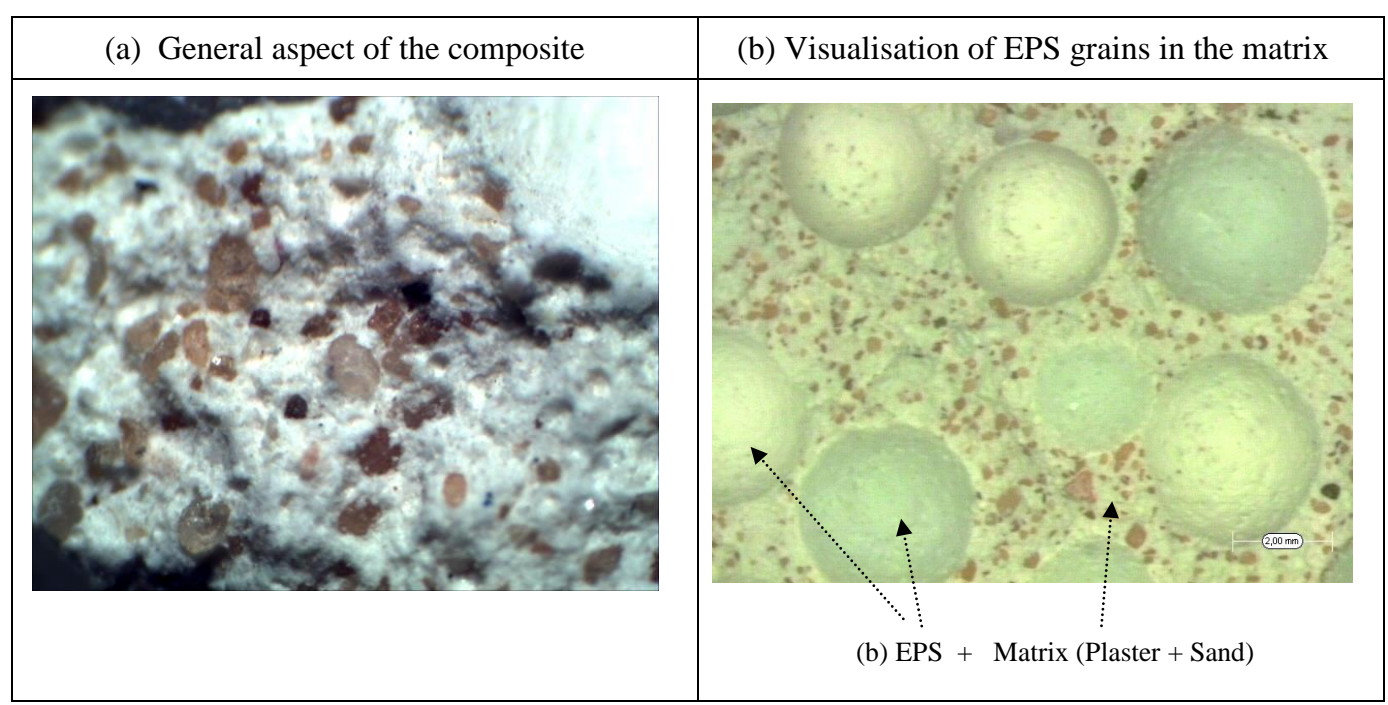

Fig. (10). Visualization at different scales of the plaster composite containing EPS beads and dune sand.



$\mathrm{G}=2000$

(a) Plaster-sand

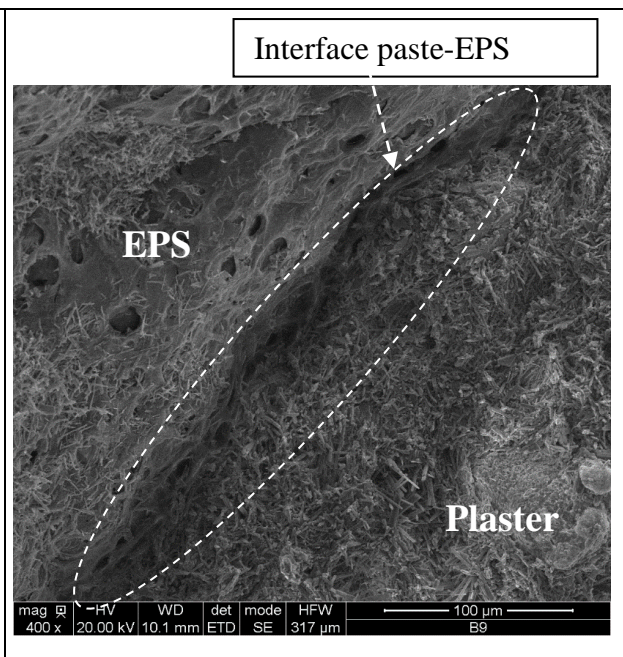

$\mathrm{G}=400$

(b) Plaster-EPS

Fig. (11). SEM analysis of EPS-based plaster composite.

\subsection{Comparison with Literature}

Let us note that all the obtained results are consistent with those obtained with the introduction of the polystyrene aggregates in cementitious matrices.

Herki et al. studied a cement lightweight concrete using different proportions of polystyrene aggregates and also showed that the increase of the proportion of the polystyrene decreased the density of the concrete [21]. Even with the introduction of cork aggregates, which have a similar aspect with the polystyrene, in cementitious matrix, Ziregue et al. [20] found that the density of the lightweight concrete decreased with the increase of the quantity of the cork particles introduced are further detailed in the following subsections.

Let us note that, according to the literature, it is possible to increase the mechanical strength of the studied material. In the case of the use of polystyrene with binders other than the plaster, Babu et al. had increased the strength by mixing the fly ash into the EPS concrete and the silica fume into the EPS concrete [1]. Chen et al. introduced a premix method to avoid the segregation of the expanded polystyrene particles during casting and reinforced their concrete by the addition of steel fibers [22]. Finally, it should be noted that Babu and Bing Chen et al. also showed that the introduction of polystyrene aggregates in cementitus composites increased its energy absorption capacity [1, 15].

Regarding to the thermal conductivity, San-Antonio-González et al. [7] and Chen et al. [22] as well as Sotehi et al. 
[23] also found that this property decreases when the quantity of EPS with the addition of expanded polystyrene to the cement concrete. Even with lime composites based on "olive stone" the same observation has been made [24].

In addition all the observations made on the general aspect and the structure of the studied material, were also observed by San-Antonio- Gonzalezetal in his study led on a lightweight material made with gypsum and extruded polystyrene waste [7]. Wenbo and shi also showed that the expanded polystyrene particles adhere well to the cementitious matrix and even remained intact after the destruction of the samples [25].

At the microstructural level, it should be noted that San-Antonio-González et al. also observed similar crystal needles which were formed by the hydration of the gypsum in the presence of extruded polystyrene waste. They even confirmed that the cohesion between the gypsum and the extruded polystyrene beads is good [7].

\section{CONCLUSION}

It is an experimental work where a plaster composite based on polystyrene beads and dune sand was investigated. It aims at studying the influence of the addition of different percentages and different particles sizes of expanded polystyrene beads on the physicomechanical properties of the studied plaster composite. The following conclusions can be drawn:

- The introduction of the polystyrene beads in a matrix made of 'plaster-dune sand' led to low densities which were between 613 and $1414 \mathrm{~kg} / \mathrm{m}^{3}$ for polystyrene contents between 0 and $50 \%$; compared to the control composite (Without polystyrene beads), a decrease in the bulk density of about $56.7 \%$ was recorded.

- Depending on the proportion of polystyrene beads introduced, a decrease in the mechanical strength, was recorded; in compression, a reduction of about $77.30 \%$ was recorded with a content of $50 \%$ of polystyrene beads with particles $(5-7 \mathrm{~mm})$, and the best results are the ones obtained with the finer particles.

- The thermal conductivity of the composite is significantly improved (decreased) by the addition of the polystyrene beads. With a percentage of $50 \%$ polystyrene for the particle size $5-7 \mathrm{~mm}$, it was possible to obtain thermal conductivities lower than $0.2 \mathrm{~W} \cdot \mathrm{m}^{-1} \cdot \mathrm{K}^{-1}$. Once again, best results are those of the finer particle sizes.

- Between the different EPS particle sizes studied, size $3.15 \mathrm{~mm}$ gave the best results.

- Generally, the obtained composite seems to be relatively homogeneous with a good adhesion 'polystyrene matrix" and "sand - plaster paste".

- The microstructure analysis showed that only needles are developed in the plaster paste after hydration.

- Finally, it should be noted that this lightweight material with improved thermal behaviour can perfectly find its use in the manufacture of prefabricated plaster blocks for partitioning.

\section{CONSENT FOR PUBLICATION}

Not applicable.

\section{CONFLICT OF INTEREST}

The authors declare no conflict of interest, financial or otherwise.

\section{ACKNOWLEDGEMENTS}

Not applicable.

\section{REFERENCES}

[1] K. Ganesh Babu, and D. Saradhi Babu, "Behaviour of lightweight expanded polystyrene concrete containing silica fume", Cement Concr. Res., vol. 33, pp. 755-762, 2003. [http://dx.doi.org/10.1016/S0008-8846(02)01055-4]

[2] R. Demirboga, and A. Kan, "Thermal conductivity and shrinkage properties of modified waste polystyrene aggregate concretes", Constr. Build. Mater., vol. 35, pp. 730-734, 2012. 
[http://dx.doi.org/10.1016/j.conbuildmat.2012.04.105]

[3] V. Ferrándiz-Mas, and E. García-Alcocel, "Physical and mechanical characterization of Portland cement mortars made with expanded polystirene particles addition (EPS)", Mater. Constr., vol. 62, no. 308, pp. 547-566, 2012.

[4] V. Ferrándiz-Mas, and E. García-Alcocel, "Durability of expanded polystyrene mortars", Constr. Build. Mater., vol. 46, pp. 175-182, 2013. [http://dx.doi.org/10.1016/j.conbuildmat.2013.04.029]

[5] V. Ferrándiz, "Design of cement mortars with addition of expanded polystyrene (EPS) polymeric waste", PhD Thesis, University of Alicante, Alicante, 2013.

[6] K. Ganesh Babu, and D. Saradhi Babu, "Properties of lightweight expanded polystyrene aggregate concretes containing fly ash", Cement Concr. Res., vol. 35, pp. 1218-1223, 2005. [http://dx.doi.org/10.1016/j.cemconres.2004.11.015]

[7] A. San-Antonio-González, M. Merino, C. Arrebola, and P. Villoria-Sáez, "Lightweight material made with gypsum and EPS Waste with enhanced mechanical strength", J. Mater. Civ. Eng., vol. 4, pp. 432-442, 2016.

[8] M. Bederina, B. Belhadj, M.S. Ammari, A. Gouilleux, Z. Makhloufi, N. Montrelay, and M. Quéneudéc, "Improvement of the properties of a sand concrete containing barley straws - Treatment of the barley straws", Constr. Build. Mater., vol. 115, pp. 464-477, 2016. [http://dx.doi.org/10.1016/j.conbuildmat.2016.04.065]

[9] M. Bederina, M. Hadjoudja, R.M. Dheilly, Z. Makhloufi, and M. Quéneudec, "Combined effect of sand grain size and contents of wood and filler on the physicomechanical properties and the microstructure of lightweight sand concrete", J. Adhes. Sci. Technol., vol. 30, pp. 1391-1412, . [http://dx.doi.org/10.1080/01694243.2016.1146390]

[10] D.J. Hasler, T.D. Wheelock, L.K. Doraiswamy, and K.P. Constant, "Physical properties and composition effects on the reactivity of calciumbased sulfur sorbents", Ind. Eng. Chem. Res. Vom., vol. 46, pp. 5913-5921, 2007. [http://dx.doi.org/10.1021/ie061561n]

[11] EL Abdelmajid, Bouardi, Hassan Ezbakhe, Taib Ajzoul, Volker Wittwer, "Thermophysical proprietés during the changment of the granular compact Structure. Measurements and identifications; application to deformable expanded matrix at air: Case of the vermiculite and the polystyrene, Journées Internationales de Thermique, Tanger, Maroc, 15-17 Novembre 2005).

[12] SSEN. "22007-2: 2008, "Plastics-Determination of thermal conductivity and thermal diffusivity-Part 2: Transient plane heat source (hot disc) method", International Organization for Standardization., ISO: Geneva, Switzerland, 2008.

[13] CNERIB, Recommandations pour la construction en plâtre, Recommendations for construction with Plaster, Ministère de l'hostat, 1993, Algeria.

[14] UNE-EN 13279-1:2009 gypsum binders and gypsum plasters. Part 1: Definitions and requirements., AENOR: Madrid, 2009.

[15] RILEM, Commission des bétons légers. Terminologie et définition. Matériaux et construction (Terminology and definition. Materials and Construction). , pp. 60-69, 1970.

[16] ACI 213R87, Guide for structural lightweight aggregate concrete, 1 CI Manual of Concrete Practice, Part I: Materials and General Properties of Concrete, Detroit, Michigan, 1994.

[17] K.G. Babu, and S.B. Babu, "Performance of fly ash concretes containing lightweight EPS aggregates", Cement Concr. Compos., vol. 26, pp. 605-611, 2004.

[http://dx.doi.org/10.1016/S0958-9465(03)00034-9]

[18] S.H. Perry, P.H. Bischoff, and K. Yamura, "Mix details and material behavior of polystyrene aggregate concrete", Mag. Concr. Res., vol. 43, pp. 71-76, 1991. [http://dx.doi.org/10.1680/macr.1991.43.154.71]

[19] R.S. Ravindrarajah, and A.J. Tuck, "Properties of hardened concrete containing treated expanded polystyrene beads", Cement Concr. Compos., vol. 16, pp. 273-277, 1994.

[http://dx.doi.org/10.1016/0958-9465(94)90039-6]

[20] A. Ziregue, and M.M. Khenfer, "Michèle Quéneudec-t'Kint \& Nicolas Montrelay, "Developmental potentiality of insulating lightweight concrete based on cork and calcareous sand", J. Adhes. Sci. Technol., vol. 30, 2016. [http://dx.doi.org/10.1080/01694243.2015.1129882]

[21] B.A. Herki, J.M. Khatib, and E.M. Negim, "Lightweight concrete made from waste polystyrene and fly ash", World Appl. Sci. J., vol. 21, pp. 1356-1360, 2013.

[22] B. Chen, and J. Liu, "Properties of lightweight expanded polystyrene concrete reinforced with steel fiber", Cement Concr. Res., vol. 34, pp. 1259-1263, 2004. [http://dx.doi.org/10.1016/j.cemconres.2003.12.014]

[23] N. Sotehi, and A. Chaker, "Thermal performance characterization of lightweight concrete", Incorporated with polystyrene study of civil engineering and architecture (SCEA)., vol. 3, 2014.

[24] F. Barrece, and C.R. Fichera, "Use of olive stone as an additive in cement lime mortar to improve thermal insulation", J. Energy Build., vol. 62 , pp. 507-513, 2013. 
[25] W. Shi, L. Miao, J. Luo, J. Wang, and Y. Chen, "Durability of modified expanded polystyrene concrete after dynamic cyclic loading", Hindawi Publ. Corp., vol. 2016, p. 7, 2016.

\section{(C) 2018 Laoubi et al.}

This is an open access article distributed under the terms of the Creative Commons Attribution 4.0 International Public License (CC-BY 4.0), a copy of which is available at: https://creativecommons.org/licenses/by/4.0/legalcode. This license permits unrestricted use, distribution, and reproduction in any medium, provided the original author and source are credited. 